\title{
The Practice of the Modern Apprenticeship Education Model in the Training of Pharmaceutical Professionals in Higher Vocational Colleges*
}

\author{
Weinan Pan \\ Scientific Research and Development Planning Department \\ Hunan Food and Drug Vocational College \\ Changsha, China
}

\author{
Shuixiu Deng** \\ College of Pharmacy \\ Hunan Food and Drug Vocational College \\ Changsha, China \\ $* *$ Corresponding author
}

\begin{abstract}
Based on the requirements of the reform of talent cultivation in higher vocational education and the connotation of modern apprenticeship, this paper designs a modern apprenticeship practice model of "full cooperation and education, full cooperation, and full employment" of school-enterprise cooperation and talent education. Schools and enterprises jointly set up a modern apprenticeship pilot working group to build a cultivation platform of basic theoretical knowledge and professional practice for students through the cooperation of schools and enterprises in the aspects of training objectives, human training programs, curriculum systems, teaching operations, assessment and appraisal, and apprenticeship employment for the common development of skills promotes student employment, the company's talent pool, and the quality of higher vocational education.
\end{abstract}

Keywords-modern apprenticeship; higher vocational pharmacy professionals; school-enterprise cooperation; coeducational talent

\section{INTRODUCTION}

In 2005, China put forward the decision to vigorously develop vocational education, and called for the establishment of a modern occupation education system with Chinese characteristics, which is closely integrated with market demand and employment, characterized by school-enterprise cooperation and work-study combination, and has a reasonable structure, flexibility, openness, and self-development. In 2014, the Ministry of Education put forward the "Opinions on the work of Developing a Pilot Project for Modern Apprenticeship" to speed up the integration of production and education in vocational education and school-enterprise cooperation, and proposed a brand-new model for further improving the personnel training mechanism for schoolenterprise cooperation.

General Secretary Xi Jinping clearly stated in the report of the 19th CPC National Congress: Improve the vocational education and training system, deepen the integration of

*Fund Project: This is the research result of the "Research and Practice of Modern Apprenticeship in Pharmacy Specialty in Vocational Colleges" (No. SYHZW201721) of the Policy Research Committee of the National Food and Drug Vocational Education Teaching Steering Committee. production and education, and school-enterprise cooperation. Recently, the General Office of the State Council issued the "Several Opinions on Deepening the Integration of Production and Education", and further clarifying the direction and goals for advancement task in deepening the reform of modern vocational education under the new situation, giving play to the important role of the enterprise, cultivating a large number of high-quality innovative talents and technical and technical talents.

Higher vocational colleges are committed to cooperating with the industry enterprises to invigorate and in-depth cooperation, carry out modern apprenticeships and practice, open new idea of school-enterprise cooperation and cocultivate talent with co-cultivate talent in the whole process, co-cultivate throughout the entire process, and cooperate in employment in the whole process. New ideas for educating talents. The pharmacy profession has a close connection with the pharmaceutical industry. This kind of industry has a high requirement for the practice of practitioners. To solve the problem of students' practical skills, higher vocational pharmacy majors apply modern apprenticeship, and rely on cooperation between schools and enterprises to enable students to master more basic knowledge, professional skills and professional competence required for more jobs related to pharmaceuticals.

\section{OVERVIEW OF MODERN APPRENTICESHIP}

Modern apprenticeship is the new apprenticeship system. It is a modern vocational education system that combines the traditional apprenticeship mode and the modern school education, which is a modern personnel training models based on the advantages of the traditional apprenticeship. Through the deep cooperation between schools and enterprises, teachers and teachers the company's masters teach together to cultivate students' practical training skills. In terms of the number of years of study, students have $1 / 3$ of the time to learn basic theoretical knowledge from school teachers, $2 / 3$ of the study time is spent in the enterprise, and they are trained by the company's masters. School and enterprise cooperate in the development of learning content and training contracts, the company sent teachers to the students in the enterprise training 
process and results guide and supervise. Students and businesses are bound by apprenticeship contracts, and students are apprentices. They do not need to pay tuition fees and enjoy apprenticeships during corporate learning and training.

\section{THE IMPLEMENTATION PATH OF MODERN APPRENTICESHIP MODEL IN THE CULTIVATION OF PROFESSIONAL PHARMACY PROFESSIONALS}

\section{A. Choose A Partner Company and Set up A Working Group}

When choosing a cooperative enterprise, it is necessary to select medical institutions such as local well-known and firstline medical manufacturing companies, operating companies, circulation companies, and hospitals as partners on the basis of service areas and local economies, and commit themselves to serving regional economic development. School heads, professional team teachers, co-operative managers, and corporate technologists form an apprenticeship training team and are responsible for all the work arrangements for modern apprenticeship pilots.

\section{B. Clarify Talent Development Objectives}

Schools and enterprises shall formulate clear personnel training goals in accordance with the requirements of both parties and the specific conditions of the students. Students shall be required to master basic medical theory knowledge, relevant laws and regulations, and develop practical skills training targets according to their needs. For example, pharmaceutical production enterprises students are required to master certain skills such as production of pharmaceutical preparations, quality control of pharmaceuticals, and quality assurance inspection. On the basis of grasping the basic pharmaceutical production processes and quality control processes, they can combine the main products of the cooperative enterprises to master the production and quality control procedures of the products of the company. Drug trading and management companies need to master the basic processes of pharmacy operations and management, be able to respond to necessary professional skills such as rational drug counseling and publicity and education, and be able to adapt to the pharmaceutical sales, business management, and drug use consulting required by front-line retail drugstores at all levels and health guidance and other work [1]. Each hospital's pharmacy department needs students to have basic knowledge of drug library management, drug distribution, medication guidance, and vein configuration. All types of enterprises also need to conduct corresponding professional ethics education for students.

\section{Choosing the Right Recruitment Method}

The modern apprenticeship recruiting targets include formal recruitment of employees, new students enrolled in the school, and secondary students selected by the secondary school. After students complete the compulsory basic medical science courses, they are selected according to their own employment intentions. Students who are interested in employment in cooperative enterprises should also be recruited while they select the professionals. When the spring and autumn semester begin at the beginning of each school year, students can be recruited. According to the identity of the recruited person, their apprenticeship status or the dual status of the student and the apprentice can be clearly defined. Students, apprentices, and business training agreements and school-enterprise cooperation protocol can be signed.

\section{Formulating Talent Development Program}

Both schools and enterprises participate together to highlight the corresponding skills training in the cultivation of practical skills in the talent training program according to the post-competency needs of the partner companies. On the basis of adapting to the needs of enterprises and serving the pharmaceutical industry, with the goal of system promotion and system training, students or apprentices are targeted and their specific positions are clearly defined. School teachers and enterprise masters jointly formulate training plans after consultation. The actual case of the cooperative enterprise is used as the teaching carrier of the public quality curriculum, and case-based teaching is adopted to improve students' professional ethics, professional quality, interpersonal communication skills, and teamwork ability. The basic course of medicine adopts a combination of theory and practice for teaching, and provides students with relevant training content for practicing pharmacist qualification examination. The related technical courses required by the cooperative enterprises adopt a project-centered teaching method that fits the actual situation of the company [2].

\section{E. Scientific Design Course System}

Based on the dual-teaching system, the school and the enterprise both formulate professional courses based on the job requirements of the docking company, formulate professional course teaching programs, and formulate professional course systems based on the typical working process to establish jobbased skills requirements and qualification standards for licensed pharmacists. In accordance with the professional curriculum system, strengthen the work-study exchange, enhance the content and requirements of the practical teaching, and take targeted instruction and teaching according to the different requirements of the company's job assignment and professional ability. In the curriculum system, corporate culture is taken as the carrier of the curriculum. The rules and regulations, production management methods, pharmacists' working methods, and management methods of the docking companies should be integrated into the teaching content of the course. The instructors should be in accordance with the production personnel, quality control personnel, the requirements of pharmacists and business personnel in stores are standardized, and students are trained according to the requirements of actual operators and pharmacists. In the course system and teaching operation, the enterprise management culture and medical health culture are integrated so that the students can truly have the comprehensive qualities required by the basic literacy of the pharmacy students in the higher vocational colleges and the cooperative enterprises [3].

\section{F. Effective Management of Teaching Operations}

The teaching operation may be optional in the training college of the cooperative enterprise, or in the training room in 
the school and the enterprise work environment simulation. The full-time teacher and the partner will join the class as the head teacher, and be responsible for coordinating the training time of the teacher and the student each month. In addition, the curriculum arrangements are made well in advance. The company will arrange a full-time person in charge to assist the head teacher in daily teaching management. The study time should be more than 2 weeks of corporate apprenticeship time per semester, and the first and second semesters should be arranged by the company for 2-3 weeks and 4-5 weeks on the basis of public quality courses and professional foundation courses. The corresponding post can be arranged by the company or according to the students' own wishes. In the third semester, school full-time teachers and enterprise technical experts jointly conduct the teaching of professional post courses. At the same time, the company is responsible for the implementation of project training for more than six weeks, familiar with the company's basic work flow guidance and supervision of the company's master during the whole process. In the fourth semester, in addition to the technical experts assigned by the cooperative companies, the technical masters of the corresponding professional posts complete the teaching of the technical courses. The masters of the enterprises guide the students to complete the rotational training for more than eight weeks in the company and be familiar with the basic work flow of each post, and the students In the process of rotational training, we will further select jobs that are more interesting to them and prepare for the internships for companies in the fifth and sixth semesters. Students will further develop professional theories and practical skills in the internship practice, and will be closely connected with the real work process. So that after the end of learning can go directly to work.

\section{G. Innovative Student Assessment Mechanism}

Schools and enterprises both implement dual-system assessment methods according to the actual training of students. Schools and enterprises are the subject of evaluation. They assess the students' professional ability, social ability, and professional skills, and are combined with the requirements of the company. The public quality curriculum is evaluated by the company based on the students' cognition and practice in case teaching combined with the actual situation of the company and the teaching requirements of the school. The professional basic curriculum is evaluated jointly by the school full-time teachers and enterprise technical experts according to the teaching requirements; the post technical courses are mainly managed by the company. With assessments and process assessment methods, students are assessed according to their attendance, workload, work attitude, work discipline, work ability, and quality cost. Each semester's apprenticeships are included in the semester's assessment of the total appraisal. Education and employee assessment are organically integrated in student assessments, and the proportion of employee assessments throughout the assessment is gradually increased. During the training of students, the school and the enterprise participate in the evaluation of professional skills assessment. Before graduation, students need to obtain academic certificates and related post vocational qualification certificates.

\section{H. Promoting Student Employment and Entrepreneurship}

Through modern personnel training methods for apprenticeships, enterprises can solve the problems of talent selection, cultivation, employment and retention faced during transformation and upgrading. Enterprises can assess students every quarter in the process of apprenticeship development and practice at the internship positions. According to the students' learning situation, occupational hobbies and practical abilities, enterprise can select a group of students with solid professional theories, who love the pharmaceutical industry, have great potential for development and higher overall quality as reserve cadres, to focus on training, and make students become a source of talent pool for enterprises. So it will ake the workforce more stable, and also enables students to have higher learning enthusiasm and career expectations [4]. During the cultivation of students, schools and enterprises must encourage students to innovate and entrepreneurship, and cultivate more students who are more in line with their actual capabilities and development needs, so that they can have greater advantages in employment.

\section{CONCLUSION}

At present, many medical vocational colleges are conducting trials of modern apprenticeships in the pharmacy profession. However, they are given to schools and companies in terms of dualistic management, dual-professional training, student teaching management, student induction training, and excessive apprentice mobility. It comes with greater management difficulty and risk. In order to further improve the modest stability of modern apprenticeship, top-level design should be carried out from the policy level, the role of the pharmaceutical industry association should be brought into play, the innovative talents training model and teaching management mechanism in higher vocational colleges, and the quality of teaching and training of cooperation between colleges and enterprises should be improved. Starting from the job content, we will innovate the modern apprenticeship training program and curriculum system, give full play to the roles of school teachers and enterprise masters, and build new ways and models for the reserve of talents in medical enterprises and students cultivation in higher vocational colleges.

\section{REFERENCES}

[1] Yuan Haijian, Wang Hui, Zhou Tao. Construction of a talent training model based on modern apprenticeship for pharmacy specialty retail pharmacies [J]. Chinese Pharmacy, 2015, 26(36):5162-5164.

[2] Li Feng, Cheng Jin, Wang Ning, etc. Preliminary research on the effectiveness of modern apprenticeship in pharmacy majors of higher vocational health colleges-Taking Yancheng Hygiene Vocational and Technical College as a five-in-one dualistic model as an example [J]. Health Vocational Education, 2017, 35(8):11-12.

[3] Diao Aiqin, Chen Guofu, Pan Aiping. Relying on the core curriculum, the introduction of industrial corporate culture into higher vocational pharmacy teaching reform [J]. Anhui Medicine, 2016, 20(10): 2003 2006.

[4] Li Chunling. Career Planning Guidance Research for Pharmaceutical Majors under the Modern Apprenticeship Pilot Project [J]. New Curriculum Research, 2017(1):127-128. 